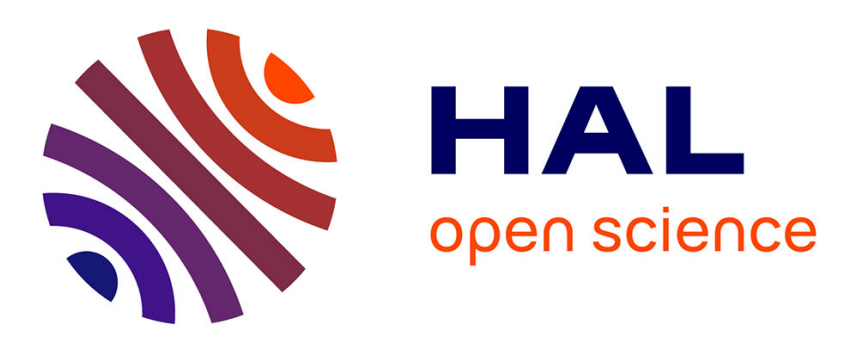

\title{
Self-assembly of three-dimensional photonic crystals on structured silicon wafers
}

Patrick Ferrand, M. Egen, B. Griesebock, J. Ahopelto, M. Müller, R. Zentel, S. G. Romanov, C. M. Sotomayor Torres

\section{- To cite this version:}

Patrick Ferrand, M. Egen, B. Griesebock, J. Ahopelto, M. Müller, et al.. Self-assembly of threedimensional photonic crystals on structured silicon wafers. Applied Physics Letters, 2002, 81 (15), pp.2689-2691. 10.1063/1.1513212 . hal-00278072

\section{HAL Id: hal-00278072 \\ https://hal.science/hal-00278072}

Submitted on 15 Apr 2015

HAL is a multi-disciplinary open access archive for the deposit and dissemination of scientific research documents, whether they are published or not. The documents may come from teaching and research institutions in France or abroad, or from public or private research centers.
L'archive ouverte pluridisciplinaire HAL, est destinée au dépôt et à la diffusion de documents scientifiques de niveau recherche, publiés ou non, émanant des établissements d'enseignement et de recherche français ou étrangers, des laboratoires publics ou privés. 


\title{
Self-assembly of three-dimensional photonic crystals on structured silicon wafers
}

\author{
P. Ferrand ${ }^{\text {a) }}$ \\ Institute of Materials Science and Department of Electrical and Information Engineering, \\ University of Wuppertal, Gaußstraße 20, D-42097 Wuppertal, Germany \\ M. Egen and B. Griesebock \\ Institute for Organic Chemistry, Department of Chemistry and Pharmacy, University of Mainz, \\ Duesbergerweg 10-14, D-55099 Mainz, Germany \\ J. Ahopelto \\ VTT Centre for Microelectronics, P.O. Box 1208, FIN-02044 VTT, Finland \\ M. Müller and R. Zentel \\ Institute for Organic Chemistry, Department of Chemistry and Pharmacy, University of Mainz, \\ Duesbergerweg 10-14, D-55099 Mainz, Germany
}

S. G. Romanov and C. M. Sotomayor Torres

Institute of Materials Science and Department of Electrical and Information Engineering, University of Wuppertal, Gaußstraße 20, D-42097 Wuppertal, Germany

(Received 17 June 2002; accepted 20 August 2002)

\begin{abstract}
The growth of an opal-like polymer photonic crystal $(\mathrm{PhC})$ on deeply etched silicon wafers is reported. It is shown that $10 \mu \mathrm{m}$ deep trenches, as narrow as $10 \mu \mathrm{m}$ can be uniformly filled by self-assembly of microspheres, in a close-packed face-centered-cubic lattice. These observations are confirmed by optical reflectance measurements in the visible range, in agreement with theoretical calculations of the photonic band gap. A slight fluctuation of the lattice parameter is noticed in the case of the narrowest channels. The possibility to detach the $\mathrm{PhC}$ from the substrate is also demonstrated. The potential of this approach for building complex PhC-based complex architectures is discussed. (C) 2002 American Institute of Physics. [DOI: 10.1063/1.1513212]
\end{abstract}

The strong research effort devoted to photonic crystals $(\mathrm{PhCs})$ is motivated by their potential to build a generation of optoelectronic devices of reduced size, combining high integration, and high-speed processing. ${ }^{1}$ In this context, close packages of monodisperse microspheres, also called opals, constitute a promising approach to fabricate threedimensional (3D) $\mathrm{PhCs}$, in its bare ${ }^{2}$ or in an inverted form following a template approach, ${ }^{3}$ at low cost and large scale required by mass production. Several ways to control the early stage of sedimentation have been already reported, using either patterned substrates ${ }^{3}$ (also grooves ${ }^{4}$ and pyramid shaped pits) ${ }^{5,6}$ or an electrically driven deposition. ${ }^{7}$ Advanced photonic circuits will need complex architectures, a sufficient number of spheres to ensure a photonic band gap effect in all directions, as well as electrically addressable materials.

In this letter, a 3D PhC self-assembly on deeply etched silicon wafers is reported. After the experimental details, we describe our sample from a structural point of view, emphasizing the ordering of the spheres. Then, the optical properties are investigated. Finally, the issue of cracks is discussed.

The (100) silicon substrate wafer was etched in an inductively coupled plasma reactor, to a typical etch depth of $10 \mu \mathrm{m}$. It was cleaned by a standard process, hydrophilized in a $\mathrm{H}_{2} \mathrm{O}_{2}(35 \%): \mathrm{NH}_{3}(25 \%): \mathrm{H}_{2} \mathrm{O}(1: 1: 5)$ bath for $3 \mathrm{~h}$, and rinsed in deionized water. The sedimentation was performed

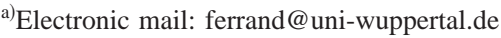

by drawing up the wafer in a vertical position ${ }^{8}$ with a velocity of about $300 \mathrm{~nm} / \mathrm{s}$ from a $3 \mathrm{wt} \%$ suspension of monodisperse poly(methylmethacrylate) (PMMA) spheres of diameter abound $280 \mathrm{~nm}$, prepared following the routine described elsewhere. ${ }^{9}$ All processes were carried out at room temperature. Optical reflectance was measured using a Dilor XY 800 triple spectrometer equipped with a microscope, in a front white-light illumination configuration, through an intentionally low numerical aperture $(0.25)$ objective $(\times 10$ magnification). Care was taken to set the slits in order to select, from the surface of the sample, an effective area of $50 \times 50 \mu \mathrm{m}^{2}$. Spectra were corrected by the response of the whole optical system. Prior to their observation by a Philips XL30 scanning electron microscope (SEM), the samples were cleaved for side observations and sputtered with a thin film $(10 \mathrm{~nm})$ of gold.

Since the thickness of the deposited film depends on the concentration of the colloid suspension and on the drawing velocity, ${ }^{8}$ it was possible to match the trench etch depth. As shown on side view SEM micrographs in Fig. 1(a), the deposition is uniform and about $10 \mu \mathrm{m}$ thick. Moreover, it appears, in Fig. 1(b), that the unetched areas remain uncovered. This can be easily understood considering the vertical geometry used for the crystallization process. The deposition of spheres takes place at the top of the meniscus. ${ }^{8,10}$ Since this meniscus is higher within the trenches due to stronger capillary forces, the colloids are drained there and no crystallization occurs on unetched silicon area. 

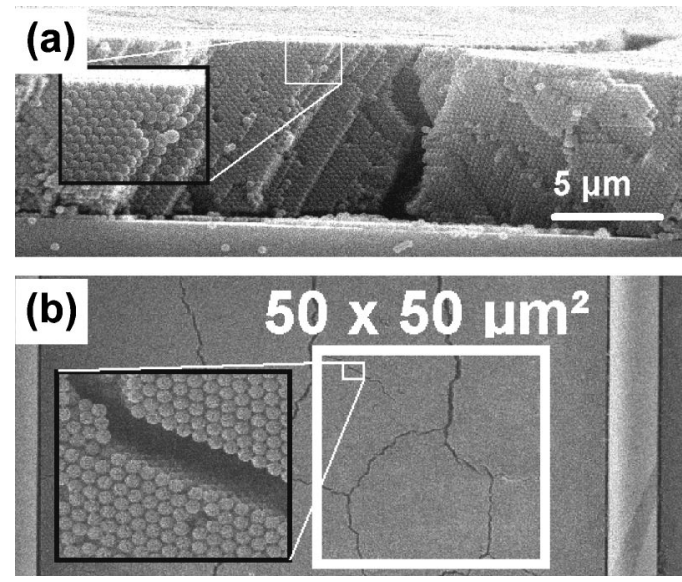

FIG. 1. (a) Side view SEM micrograph of a self-assembled 3D PhC in a 200 $\mu \mathrm{m}$ wide trench. (b) Top view, taken in another wide trench. The bright region at the right-hand side is nonetched substrate. The thick white square represents the area where optical measurements were carried out. In both cases, insets are closeups showing the almost perfect ordering.

The channels of Fig. 1 are wider than $100 \mu \mathrm{m}$. Both side [Fig. 1(a)] and surface [Fig. 1(b)] views clearly show an almost perfect closed package, in a face-centered-cubic (fcc) lattice with the [111] growth direction perpendicular to the surface of the substrate, similar to what is usually obtained on unpatterned substrates. ${ }^{8}$ Narrow trenches, having a width at least equal to the thickness, were also studied. The SEM micrographs are shown in Fig. 2. In this case, it is noticeable that the ordering still exists, even if some fluctuations of the lattice parameter appear on the top view [Fig. 2(b)].

Then, these structural observations were complemented by reflectance measurements carried out perpendicular to the sample surface, in regions illustrated in Figs. 1(b) and 2(b), respectively. Both spectra in Fig. 3, show Fabry-Perot interference fringes as proof of the uniform total optical thickness of the $\mathrm{PhC}$, and a Bragg reflection at wavelengths around $620 \mathrm{~nm}$, as a proof of the periodic nature of the PhC. The wavelength of the Bragg reflection and the relative bandwidth $\Delta \lambda / \lambda=5.5 \%$ in the wide channel case (Fig. 3, thick line), are in good agreement with the theoretical estimate of the stop band along the [111] direction for PMMA spheres of refractive index $n=1.489$, close packed in a fcc lattice (fill-

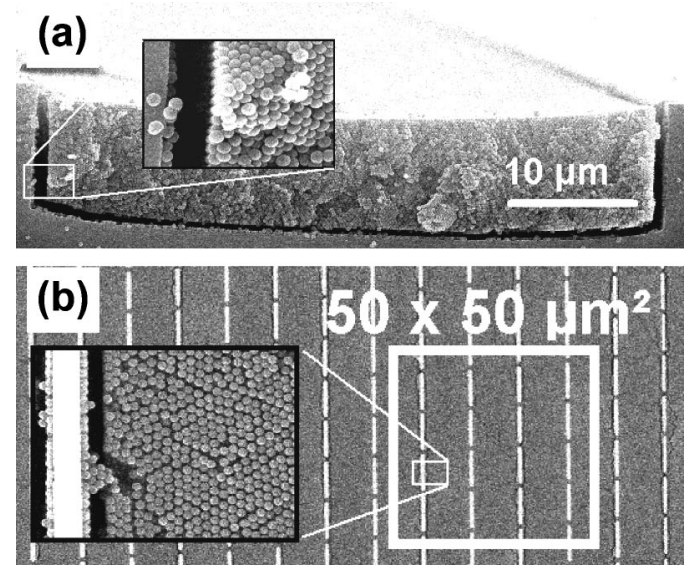

FIG. 2. (a) Side view and (b) surface SEM micrographs of self-assembled 3D PhCs in narrow trenches: (a) a $50 \mu \mathrm{m}$ wide trench and (b) a set of parallel $10 \mu \mathrm{m}$ wide trenches. The thick white square represents the area where optical measurements were carried out. The insets are closeups.

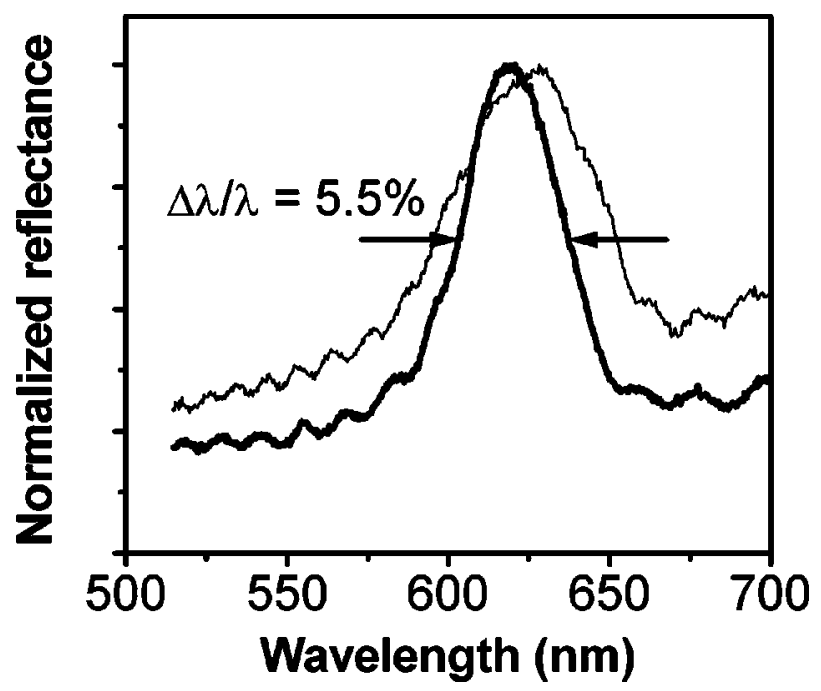

FIG. 3. Reflectance spectra recorded within regions mentioned in Fig. 1(b) (thick line) and in Fig. 2(b) (thin line).

ing fraction $74 \%) .{ }^{11}$ The Bragg peak of the sample grown on the narrow channel [Fig. 2(b)] appears slightly broader (Fig. 3 , thin line, $\Delta \lambda / \lambda=8.5 \%$ ). This is a consequence of the slight disorder mentioned herein, which takes place both in the plane and in depth. At the moment, the reasons for this remain unclear and are currently under investigation.

Finally, the location of cracks is also strongly affected by the finite trench size. Indeed, these cracks are probably a consequence of strains induced by the shrinkage of the PMMA spheres during drying of the colloidal crystal. ${ }^{8}$ In the case of opal grown on an unpatterned substrate or in a wide trench, these cracks are almost randomly distributed over the surface. Nevertheless, a typical size of crack-free domains can be empirically predicted. In our specific case, Fig. 1 shows that this size is about a couple of hundred square micrometers. The patterned substrate is, in practice, a rigid frame which, for trenches smaller than the crack-free typical size, gives rise to large strains. These, in turn, result in cracks appearing only at the opal-substrate interfaces. This gives a guarantee of a structure free of cracks, at least in volume. This is clearly visible in Fig. 2, where cracks are exclusively
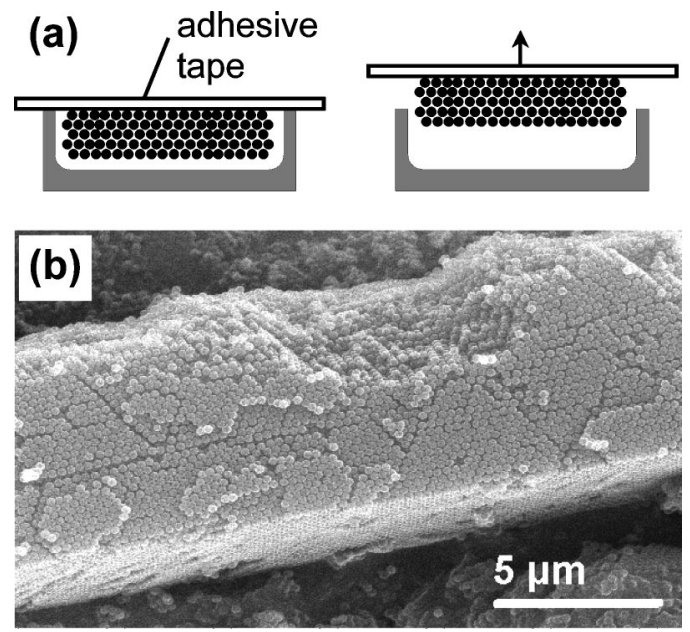

FIG. 4. (a) Scheme illustrating the procedure to detach the opal from the substrate, using an adhesive tape (cross section view). (b) Top view SEM micrograph of the detached structure, stuck on the tape. 
located along the side walls and at the bottom interface.

Moreover, more than defects, these cracks are of practical interest, since they were used to detach the opal structure from the substrate. For this purpose, an adhesive tape was placed on the sample surface, and carefully released as illustrated in Fig. 4(a). A top view SEM micrograph of the detached structure is shown in Fig. 4(b). The result resembles an elongated brick, of cross section about of $10 \times 10 \mu \mathrm{m}^{2}$, showing a straight edge and flat sides. The order seen on the top side corresponds to the early stage of the crystallization, occurring at the bottom of the trench. This provides further proof of the good global crystalline quality of the sample. The slight damage at the top edge of the crystal is due to the crude process used in this first attempt.

This approach, using the substrate as a mold and releasing the $\mathrm{PhC}$ after sedimentation, is a promising way to overcome some measurement challenges of $3 \mathrm{D} \mathrm{PhCs}$. For instance, detached structures can be investigated from the lateral sides, e. g., in- and outcoupling for waveguide measurements, without requiring sawing and polishing. Moreover, by suspending the crystal, emission studies avoiding the critical influence of the substrate will be possible. Lastly, in the prospect toward $\mathrm{PhC}$ circuits, this technique may allow the construction of complex architectures in a similar way to the multilayered integrated circuits in microelectronics, by stacking several molded $\mathrm{PhC}$ planar structures.

In summary, 3D PhC self-assembly on deeply etched silicon wafers has been reported. SEM observations showed a uniform filling of the $10 \mu \mathrm{m}$ deep trenches, as well as a close-packed ordering in a fcc lattice. These observation were confirmed by optical measurements, showing FabryPerot fringes as well as a Bragg reflection, the spectral posi- tion and width of which agreed with theoretical calculations. A slight disorder was observed in the case of the narrowest trenches. It was noticed that cracks occur preferably close the $\mathrm{PhC}$-substrate interface, giving the possibility to detach the structure from the substrate.

The authors acknowledge the support of the German Research Council (DFG) Focused Program SPP 1113 "Photonic Crystals" and of the EU IST Project PHOBOS Grant No. 19009.

${ }^{1}$ J. D. Joannopoulos, P. R. Villeneuve, and S. Fan, Nature (London) 386, 143 (1997).

${ }^{2}$ V. N. Astratov, V. M. Bogomolov, A. A. Kaplyanskii, A. V. Prokofiev, L. A. Samoilovich, S. M. Samoilovich, and Y. A. Vlasov, Nuovo Cimento D 17, 1349 (1995).

${ }^{3}$ Y. A. Vlasov, X. Z. Bo, J. C. Sturm, and D. J. Norris, Nature (London) 414, 289 (2001).

${ }^{4}$ Y. H. Ye, S. Badilescu, V. V. Truong, P. Rochon, and A. Natasohn, Appl. Phys. Lett. 79, 872 (2001).

${ }^{5}$ S. M. Yang and G. A. Ozin, Chem. Commun. 2000, 2507 (2000); G. A. Ozin and S. M. Yang, Adv. Funct. Mater. 14, 605 (2001); S. M. Yang, H. Miguez, and G. A. Ozin, Adv. Funct. Mater. 12, 425 (2002); H. Miguez, S. M. Yang, and G. A. Ozin, Appl. Phys. Lett. 81, 2493 (2002).

${ }^{6}$ Y. Yin and Y. Xia, Adv. Mater. 14, 605 (2002)

${ }^{7}$ E. Kumacheva, R. K. Golding, M. Allard, and E. H. Sargent, Adv. Mater. 14, 221 (2002).

${ }^{8}$ Z. Z. Gu, A. Fujishima, and O. Sato, Chem. Mater. 14, 760 (2002); M. Egen, B. Griesebock, R. Zentel, P. Ferrand, S. G. Romanov, and C. M. Sotomayor Torres (unpublished).

${ }^{9}$ M. Müller, R. Zentel, T. Maka, S. G. Romanov, and C. M. Sotomayor Torres, Chem. Mater. 12, 2508 (2000).

${ }^{10}$ J. Aizenberg, P. V. Braun, and P. Wiltzius, Phys. Rev. Lett. 84, 2997 (2000).

${ }^{11}$ S. G. Romanov, T. Maka, C. M. Sotomayor Torres, M. Müller, R. Zentel, D. Cassagne, J. Manzanares-Martinez, and C. Jouanin, Phys. Rev. E 63, 056603 (2001). 